\title{
Study on Transitions in Employment, Ability and Motivation (STREAM): The Design of a Four-year Longitudinal Cohort Study among 15,118 Persons Aged 45 to 64 Years
}

\author{
Jan F. Ybema ${ }^{1 *}$, Goedele A. Geuskens ${ }^{1}$, Swenne G. van den Heuvel ${ }^{1}$, \\ Astrid de Wind ${ }^{1,2,3}$, Fenna R. M. Leijten ${ }^{1,4}$, Catelijne Joling ${ }^{5}$, \\ Birgitte M. Blatter ${ }^{1,3}$, Alex Burdorf ${ }^{4}$, Allard J. van der Beek B $^{2,3}$ \\ and Paulien M. Bongers ${ }^{1,2,3}$
}

\footnotetext{
${ }^{1}$ Netherlands Organisation for Applied Scientific Research TNO, Hoofddorp, Netherlands.

${ }^{2}$ Department of Public and Occupational Health, the EMGO+ Institute for Health and Care

Research, VU University Medical Center, Amsterdam, Netherlands.

${ }^{3}$ Body@Work, Research Center on Physical Activity, Work and Health, TNO-VU/VUmc,

Amsterdam, Netherlands.

${ }^{4}$ Department of Public Health, Erasmus MC, University Medical Center Rotterdam,

Netherlands.

${ }^{5} 365 /$ Zin, Utrecht, Netherlands.

Authors' contributions
}

Authors BMB, CJ and PB took the initiative for designing the study; Authors JFY, CJ and $G A G$ designed the study, constructed the baseline questionnaire and coordinated the baseline data collection. Authors SGVDH, AJVDB and AB contributed to the construction of

the baseline and follow-up questionnaires. Authors ADW and FRML contributed to the construction of the follow-up questionnaires, and contributed to the literature reviews in this manuscript. Authors JFY, GAG and SGVDH drafted the manuscript. All authors commented on earlier drafts of the manuscript, and read and approved of the final manuscript.

Study Protocols

Received $26^{\text {th }}$ September 2013 Accepted $18^{\text {th }}$ November 2013 Published $7^{\text {th }}$ December 2013

\section{ABSTRACT}

Aims: The objective of the Study on Transitions in Employment, Ability and Motivation (STREAM) is to acquire knowledge on determinants of transitions in employment and 
work productivity among persons aged 45-64 years.

Research Framework: A research framework was developed, in which transitions in employment (e.g. leaving the workforce, entering the workforce, job change) and work productivity are influenced by the following determinants: health, job characteristics, skills and knowledge, social factors, and financial factors. Central explanatory variables in the framework are the ability to work, the motivation to work, and the opportunity to work.

Study Design: STREAM is a prospective cohort study among 12,055 employees, 1,029 self-employed persons, and 2,034 non-working persons, all aged 45 to 64 years at baseline. The study sample was stratified by age and employment status (employed, self-employed, non-working), and was drawn from an existing internet panel. The baseline measurement was carried out in 2010 (response: 70\%), and with yearly followup measurements in 2011 (response: 82\%), 2012 (response: 80\%), and 2013. At each wave, participants fill out an online questionnaire covering all aspects of the research framework.

Place and Duration of Study: The Netherlands, between October 2010 and December 2013.

Methodology: Quantitative data on all aspects of the research framework were assessed with an online questionnaire, qualitative data were assessed with interview studies, and the questionnaire data can be linked to register data at Statistics Netherlands for $89 \%$ of the participants.

Results: Transitions in employment between the first three waves of data among the participants are described.

Conclusion: STREAM will provide insight in the determinants of healthy and productive labour participation among persons aged 45 years and older, which will support the development of interventions prolonging working life in good health, while maintaining good work productivity.

Keywords: Study protocol; longitudinal cohort; older workers; transitions in employment; productivity; work ability; motivation; health.

\section{INTRODUCTION}

The workforce in the Netherlands is ageing, and a shortage of workers is expected in upcoming years because fewer young people enter the labour market and a large number of baby boomers will retire [1]. The rising ratio of retired elderly to the active working population puts pressure on public finances, and causes tension in the solidarity between generations [2]. In order to maintain the social welfare state and meet the demands of the global economy, all labour supply needs to be used, work productivity should be maintained at a high level, and sustainable employability should be promoted. In the following, sustainable employability is defined as prolonging working life in good health, while maintaining good work productivity.

In the Netherlands, the labour participation of persons aged 55 and older was traditionally low compared to younger age groups. In the past decades, various policy measures were taken to increase the labour participation of older persons, including reforms of early retirement schemes, reforms of disability and unemployment benefits, and the introduction of tax incentives to stimulate postponement of retirement [2]. The average retirement age increased from 60.8 years in 2000 to 62.8 years in 2010 [3]. Recently, Dutch Parliament 
passed a bill to gradually increase the official retirement age from 65 years to 67 years between 2013 and 2023.

The present study focuses on the determinants of sustainable employability among persons aged 45 to 64 years. In 2010, the Dutch population of 45 to 64 years consisted of approximately 2.44 million employees, 0.54 million self-employed persons, and 1.63 million non-employed persons [4]. In this study, sustainable employability is operationalized by two parameters: transitions in employment status and work productivity. Transitions in employment include: (a) transitions from work to early retirement, unemployment, and disability, (b) transitions from inactivity in the labour market to paid employment, and (c) mobility in the labour market, i.e., transitions to a different employer, transitions to a different occupation, transitions between employment and self-employment. Work productivity refers to how productive persons are while they are in a paid job.

Although an increasing number of studies address sustainable employability in an ageing society, there are several gaps in our knowledge which are primarily due to a lack of longitudinal studies in which a broad set of potential determinants are examined [5]. The Study on Transitions in Employment, Ability and Motivation (STREAM) was designed to contribute to filling these gaps, and to provide better insight into the factors that influence transitions in employment and productivity among older workers. Factors that are amenable to change through (work-related) interventions or through changes in regulations and legislation are of special interest. This knowledge will be used to support the development of interventions that increase the sustainable employability and promote labour participation among the older population in a healthy and productive way.

Stream focuses on several transitions in employment. One kind of transition in employment that we focus on is the transition from work to inactivity in the labour market, including (early) retirement, unemployment and disability for work. A recent literature review showed that relatively few longitudinal studies on early retirement have been performed until now [5]. This review reported that poor health, high physical work demands, high work pressure, low job satisfaction, and lack of physical activity in leisure time were determinants of early retirement [5]. A study among Dutch civil servants added that low appreciation at work contributed to early retirement [6]. (Training of) skills and knowledge may influence early retirement as well. Provision of and participation in education and training was associated with reduced intention to retire early and less actual retirement $[7,8]$. Furthermore, the importance of financial and social factors for early retirement has been stressed $[9,10]$. Various financial incentives, such as a lower financial reserve and a lower replacement rate as a percentage of last salary, decreased the likelihood to retire early. Employees with high support from their partner and their supervisor with respect to continuing employment, were also less likely to retire early [6].

A second kind of transition in employment that we study is transitions from inactivity to employment, including return to work from unemployment, disability for work, or retirement. A recent literature review on reemployment among unemployed persons [11] showed that several personality and individual difference variables, such as high self-esteem, and high job search self-efficacy were related to shorter unemployment duration. Moreover, psychological health problems, such as depression, lowered job search success among those unemployed. Return to work for those who are disabled for work or on long-term sickness absence, has also been found to be more likely as health problems are less severe. For example, Vlasveld and colleagues recently found that older sick-listed workers with moderate to severe depressive symptoms, high physical symptoms, high physical job 
demands and contact with medical specialists were at increased risk for a longer duration of sickness absence [12].

A third kind of transition that we focus on is mobility on the labour market, including changing jobs, changing occupation, and transitions from employment to self-employment and vice versa. Changing jobs may lead to broader and more rapid increase in knowledge and may accordingly increase sustainable employability [13]. It has been argued that structural macro-level factors (including economic conditions) determine the opportunity for job mobility, whereas individual differences affect preferences and mobility behaviours [14]. Several studies have shown that employees are more likely to change jobs if they are younger, more highly educated, in better health, and less satisfied with their current jobs [15-17].

In addition to transitions in employment, STREAM focuses on determinants of productivity. Productivity is an important aspect of functioning at work, and refers to the quantity and/or quality of the output that an individual creates. In this study, we focus on several aspects of self-reported productivity, including sickness absence, presenteeism, and loss of productivity while at work. Findings from past research demonstrate that poor health is a major determinant of decreased functioning at the workplace $[18,19]$. Many health-related factors influence productivity, including emotional well-being, self-efficacy, mastery, and coping style $[18,19]$. Other factors affecting work productivity include work-related and social factors, such as job specific demands, autonomy, flexibility, and relationships at work and in the private sphere [18-22]. These factors have also been found to influence work performance [23], a construct closely related to productivity.

Although various predictors of transitions in employment and work productivity have been identified, much essential information is still unknown. Some of the gaps in our knowledge that prevent us from designing effective interventions to prolong productive working life in good health are described below.

At present, the relative contribution of health-related factors, work-related factors, skills and knowledge, social factors, and financial factors to transitions in employment and work productivity is unclear. This is of interest because it provides insight in what interventions or regulations would potentially be most beneficial. Moreover, several factors that may push or pull workers out of the labour market have barely been studied in relation to transitions in employment, such as rewards and opportunities to continue working offered by employers (e.g. support for working longer, work adjustments) [24]. Besides, most studies have focused on the influence of (prolonged) exposure to risk factors on transitions in employment and work productivity, whereas it seems important to study the effects of changes in risk factors as well $[18,25]$. This requires a longitudinal study with a sufficient number of repeated follow-ups. This would provide insight in the window of opportunity of interventions supporting sustainable employability.

At present, it is mostly unclear why and how these risk factors influence sustainable employability. More information on the process can be obtained by examining how explanatory variables, for example the ability and motivation to work, mediate the effects of more distal determinants. Moreover, the contribution of determinants to transitions in employment and work productivity may be moderated by several demographic variables. Little is known on the age-dependency of determinants, e.g., is the influence of physical and psychological health on work productivity of workers aged 60 or older similar to their influence on productivity of middle-aged workers? Furthermore, it is largely unknown how 
factors that determine transitions in employment differ between males and females, higher and lower educated workers, between various occupations and industries. Finally, employees and self-employed persons may differ in transitions in employment and work productivity, but also in the contribution of the various determinants. Insight in these differences may be important to tailor interventions or regulations for subgroups of workers.

A substantial proportion of workers have health problems, and this proportion may further increase in the coming years. More insight is needed in how work-related factors interact with health problems, and which work-related factors enable or disable workers with health problems to continue working and to remain productive.

As all potential labour supply is needed, it is important to examine the factors that lead nonworking persons aged 45 years and older to (re)enter the workforce. Little is known about the determinants of these transitions in employment, and how they vary for different groups of non-working persons, including those who are retired, unemployed, disabled or housewives/men.

Finally, the relationship between work and health is bi-directional. In addition to insight in the influence of health on transitions in employment, more insight in the influence of work and working conditions on health in older workers is essential to support the prolongation of working life in good health.

To fill these gaps in our knowledge, we designed the Study on Transitions in Employment, Ability and Motivation (STREAM). The objective of STREAM is to acquire knowledge on determinants of transitions in employment and on determinants of work productivity, among persons aged 45-64 years. This knowledge will support the development of work-related interventions or regulations promoting sustainable employability among older workers. In designing the study several theoretical perspectives were used, the most important ones are summarized below. Fig. 1 presents our research framework.

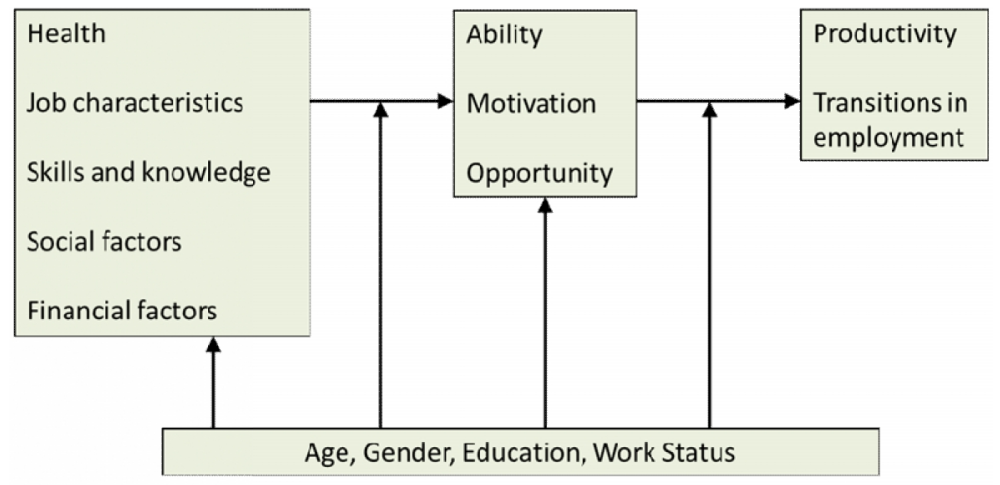

Fig. 1. Framework to investigate the determinants of transitions in employment and work productivity

In the research framework, based on the literature described above, five groups of potential determinants of transitions in employment and work productivity are distinguished. These are health, job characteristics, skills and knowledge, social factors, and financial factors. Following the WHO-definition [26], health not only includes the presence or absence of disease, but also includes subjective physical and mental health, and vitality. Job 
characteristics are divided into job demands and job resources, which is in line with the Job Demands-Resources Model [27]. According to this model, job demands refer to the physical, psychological, social, and organizational aspects of the job that require sustained efforts or skills (e.g. night work, using manual force, time pressure, emotional demands). Job resources include all physical, psychological, social and organizational aspects of the job that are: (a) functional in achieving work goals, (b) reduce job demands, or (c) stimulate personal growth, learning or development. Job resources include, for example, autonomy, social support, rewards, job security, and pay. Skills and knowledge refer to the kind of skills and knowledge that a worker possesses and needs for his or her job, and investments in improving these skills and knowledge. This includes the demands-abilities fit [28], jobrelated training, learning orientation, and skills obsolescence [29]. Social factors include support from the partner to continue working and non-paid social participation in society, such as volunteer work. Financial factors refer to the financial situation of the household and the opportunity to retire early from the financial point of view. The determinants may obviously influence each other, e.g. work characteristics influence health [30]. In the analyses of the data, this will be taken into account by investigating variables together.

The framework states that these determinants influence transitions in employment and work productivity through three central explanatory variables, i.e., the ability, motivation, and opportunity to work. Several conceptual models have previously stressed that behaviours such as continuing labour participation or entering the labour market are influenced by the individual's ability and motivation, and also by the opportunity to perform the behaviour. Examples are the AMO (Ability, Motivation, and Opportunity) model applied in human resource management to improve the performance of organizations [31], and the MOA (Motivation, Opportunity and Ability) model applied to the management of public health and social behaviour [32]. In STREAM, the ability to work includes the concept of work ability, as proposed by IImarinen [33], and self-efficacy for continuing (or starting) paid work, following Bandura's [34] social cognitive theory. The motivation to work includes both intrinsic and extrinsic motivations to work, following Self Determination Theory [35], and work values and their fulfilment. The opportunity to work include company measures to stimulate continued employment for older workers, social support at work for continued employment, and age discrimination.

Finally, all variables in the research framework, and their interrelations may be influenced by moderating variables, including gender, age, educational level, and initial employment status (i.e., employed, self-employed or non-employed).

\section{METHODOLOGY}

\subsection{Power Analysis}

In designing the present study, power calculations were done to determine the number of observations needed in our cohort study. We present the power calculation to establish the number of observations needed for examining the association between health and the transition from employment to (non-disability) early retirement using the first two measurements. This was done because early retirement is a major outcome variable with relatively low discriminatory power, because it is a dichotomous variable and it is relevant for only a subset of the respondents, i.e., employees aged 60 to 63 years. Other transitions, e.g., transitions to unemployment or disability pension, are relevant for all age groups, and therefore can be established with a higher power. Moreover, other outcomes, e.g., work 
productivity, are measured at a continuous level, and hence, the discriminatory power of these endpoints is higher.

When designing the present study, we estimated on the basis of the Dutch Labour Force Survey (EBB) 2008 of Statistics Netherlands, that approximately $31 \%$ of the participants aged 60 to 63 would retire early during 1 year of follow-up. Following Kahn and Sempos[36], at least a sample of 1,639 employees aged 60 to 63 years with full data would be needed to demonstrate a relationship of an odds ratio of 1.5 with poor health, which was estimated to occur in $15 \%$ of the employees, and early retirement (31\%) in persons aged $60-63$ years (alpha 0.05 , power $0.80,2$-sided). We expected a loss to follow-up of $20 \%$ in each measurement. This would mean that at least 2,049 participants aged 60 to 63 are needed at baseline to have sufficient statistical power to answer this research question using two waves of data collection.

\subsection{Sample and Study Design}

STREAM is a Dutch prospective cohort study of employed, self-employed persons, and non-working persons aged 45 to 64 years. The baseline measurement of STREAM was carried out in October and November 2010, the second wave of data collection in October and November 2011, the third wave in October and November 2012, and the final measurement in October and November 2013.

Persons included in STREAM participated in the Intomart GfK Online Panel, which consisted of approximately 110,000 persons in 2010, of whom about 35,000 were 45 to 64 years of age. Intomart GfK recruited panel members in various ways: from participants in national representative research carried out by Intomart GfK $(33 \%)$, through contacts of persons already included in the panel $(23 \%)$, or through newsletters $(26 \%)$ or banners $(2 \%)$. Moreover, persons applied for the panel themselves (16\%). Panel members received a financial incentive to fill out an online questionnaire. For every yearly completed STREAM questionnaire, the savings balance of the participant was increased by about 3.00 euros, with the exact amount depending on the time spent filling out the questionnaire. These savings could be paid out as gift vouchers or as a donation to the Red Cross. In STREAM, response by proxy (i.e., someone else in the household) was not allowed.

For the baseline measurement in 2010 , a sample of 26,601 persons was invited to participate in STREAM. Invited persons received a maximum of two reminders. Of this sample, 4,168 persons did not respond to the invitation, and 2,180 persons started but did not complete the questionnaire. For 5,065 persons, the questionnaire was stopped after a few selection questions because the relevant age / employment status category was already filled. In total, 15,118 participants completed their questionnaires, a response rate of $70 \%$ (excluding 5,065 persons for whom the questionnaire was stopped), which corresponds to $57 \%$ of the invited sample.

The non-response analysis showed that the response rate was somewhat lower among the age group of 60 to 64 years, and somewhat higher among the persons with a higher education level. No difference in response rate was identified between men and women. We consider the selection bias as minimal, and believe these small differences between respondents and non-respondents will not affect the results.

The design of the study was stratified by initial employment status and age. At baseline, the study sample consisted of 12,055 employees, 1,029 self-employed persons, and 2,034 non- 
employed persons, stratified by age group. The sample was stratified by age group because transitions in employment are strongly age-dependent, and we aimed to observe enough of the most important transitions in employment during the course of the study. Specifically, compared to the population, our study contains a relatively large number of employees aged 60 and older, which will lead to many transitions to early retirement, one of our most important transitions. Table 1 presents the distribution of employees, self-employed and non-employed persons by age at baseline.

Table 1. The age distribution and employment status of participants in STREAM at baseline

\begin{tabular}{cllll}
\hline Age group & Employee & Self-employed & Non-employed & Total \\
\hline $45-49$ years & 3,001 & 254 & 482 & 3,737 \\
$50-54$ years & 3,001 & 250 & 520 & 3,771 \\
$55-59$ years & 3,495 & 252 & 526 & 4,273 \\
$60-64$ years & 2,558 & 273 & 506 & 3,337 \\
Total & 12,055 & 1,029 & 2,034 & 15,118 \\
\hline
\end{tabular}

The primary focus of this study is on transitions in employment of employees, because employees form the largest group of persons active on the labour market, and there is great need for continued employment of employees while maintaining good productivity and good health. Self-employed persons were included in the study because they form an important and growing part of the Dutch workforce. Self-employed persons may differ in various ways from employees, e.g., in transitions in employment and work productivity, in health, job characteristics, and financial factors, and in the ability, motivation and opportunity for work. For example, it has been found that self-employed persons retire on average several years later than employees [3]. However, self-employed persons are also strongly overrepresented among the working poor [37], and it has been argued that in the Netherlands the effects of the economic recession are mainly felt by self-employed persons [38]. Non-employed persons were included in the study because they represent the unused labour supply, whose inflow in the workforce may be necessary in times of scarcity. Therefore, our study not only focusses on transitions out of the workforce, but also on transitions from non-employment to employment. The group of non-employed persons includes various subgroups, including those disabled for work, unemployed, early retired, and housewives/men.

Within each of the 12 cells of the design (employment status by age), the sample was intended to be representative of the Dutch population with respect to gender and educational level. For all cells in the design combined, this was the case, $x 2(\mathrm{df}=71)=32.6$, $p=1.00$. Individual cells were also representative with respect to gender and educational level, $\mathrm{X} 2(\mathrm{df}=5)<6.0, \mathrm{p}>0.30$, except for the cell with employees aged $60-64$ years, $\mathrm{X} 2$ $(d f=5)=23.8, p<0.001$. This cell consisted of relatively more females with low education, and less males with low and middle education than the Dutch population of employees aged 60-64 years.

Yearly data collection was performed using an online questionnaire. Persons who participated at baseline received all follow-up questionnaires, except for those explicitly indicating that they did not want to participate in the Intomart GfK panel and on-going studies anymore. In the second wave of data collection in 2011, 12,430 participants responded, which is $82.2 \%$ of the initial sample at baseline, and in the third wave of data collection in 2012, 12,057 participants responded (79.8\%). There were 10,952 participants 
(72.4\%) who participated in all three measurements. Based on previous studies performed by TNO $[39,40]$ it was expected that 50 to $60 \%$ of the baseline study population would participate in all four measurements in 2010, 2011, 2012, and 2013.

\subsection{Measurements}

The baseline online questionnaire covered a wide range of variables to cover all elements of the framework. Whenever possible, the questions asked to employees, self-employed, and non-employed persons were identical. In addition, more specific questions were asked depending on respondents' employment status (employee, self-employed, non-employed) and transitions in employment status. In total, employees were asked 206 to 220 questions, self-employed 191 to 209 questions, and non-employed persons 134 to 143 questions. The median time needed for filling out the questionnaire was 27 minutes for both employees and self-employed persons and 20 minutes for non-employed persons. In the questionnaire, validated items and scales were used whenever possible. This includes, among others, (subscales or items from) the SF12 [41], SF36-vitality [42], CES-D [43], UWES (Utrecht Work Engagement Scale) [44], JCQ [45], COPSOQ [46], NADS (Nordic Age Discrimination scale) [47], and PMS (Pearlin-Schooler Mastery Scale) [48]. Moreover, several items and scales were identical to those used in the Netherlands Working Conditions Survey (NWCS, [49]). In order to tailor the questionnaire to transitions in employment status, newly formulated questions were included as well. Several of these questions were based on findings from previous (qualitative) studies. Examples are questions on social support to continue working until the retirement age, skills and competences, and opportunities offered by the employer to continue working. At first, newly formulated questions were tested by means of interviews with 10 persons and adjusted when needed. In addition, the feasibility and acceptability of the questionnaire was assessed before study onset in a pre-test among 100 persons who participate in the Intomart Gfk internet panel. These participants in the pre-test were not invited to participate in the main study. At the yearly follow-up measurements, largely identical questionnaires were used as the baseline questionnaire. An overview of all constructs measured in the baseline questionnaire is given in Table 2 .

\subsection{Linkage to Register Data}

In the baseline questionnaire, participants were asked to give their consent to link their answers to register data from Statistics Netherlands. Such linkage enables the attainment of additional background variables, for example information about yearly income and financial property from tax authorities. Moreover, in the future, linkage may be used to follow transitions in employment and age of retirement for participants after data collection for this study is completed. Medical consumption, hospital admittance and mortality can also be examined in future linkages. Of the 15,118 participants who completed the baseline questionnaire, 13,672 gave their consent to link their answers to register data (90\%). In a test linkage at Statistics Netherlands, the data of 13,416 participants could successfully be linked to the base registration. Therefore, $89 \%$ of the sample at baseline could successfully be linked. 
Table 2. Constructs measured in the STREAM questionnaire

\begin{tabular}{ll}
\hline Framework & Constructs \\
\hline Demographics & Birth date, Gender, Ethnicity, Education, Household composition \\
Health & Diseases and work handicap[49], Quality of life (SF12[41]), Vitality \\
& (SF36[42]), Musculoskeletal complaints[49,50], Depression (CES- \\
& D10[43]), Recovery/relaxation (DISC-R)[51] \\
Job characteristics & Profession (ISCO), Industry (NACE), Working hours[49], Overtime, \\
& Evening and night work[49], Restructuring[49], Physical demand[49], \\
& Work load[45], Autonomy[45], Emotional demand[49], Mental \\
& demand[49], Social support[46], Bullying and intimidation[49], \\
& Organizational justice[52,53] \\
Skills and knowledge & Demands-abilities fit, Skills obsolescence, Learning orientation[54], \\
& Job related training \\
Social factors & Unpaid work, Employment status of partner, Social support partner[6], \\
Financial factors & Life events, Work-family balance[49] \\
& Contribution to household income[55], Financial situation of \\
household, Financial situation of company, Financial opportunity for \\
Motivation & early retirement \\
& Work values[49], Realization of work values[49], Engagement \\
& (UWES[44]), Motivation to work, Preferred retirement age[49], Job \\
Ability & satisfaction[49] \\
Work ability (WAl[56]), Capacity to work, Self-efficacy, Ability-related \\
Opportunity
\end{tabular}

\subsection{Qualitative Interviews}

In addition to the yearly online questionnaires, qualitative in-depth information is collected by means of face-to-face or telephone interviews. At the end of each yearly questionnaire, respondents were asked their consent to be contacted for these additional interview studies in the following year, and provided their contact information. In a first qualitative study, 32 persons were selected and invited for a face-to-face interview if they had made a transition from work to early retirement in the previous months or had arranged to do so in the coming months $[62,63]$. The goal of this study was to examine why respondents retired early, and more specifically how their health influenced their decision to retire. Respondents were a purposeful selection of participants, based on age, educational level, and retirement intention in the baseline measurement. In a second qualitative study, 26 persons were selected and invited for telephone interviews if they were in poor or moderate health and were still employed [64]. The goal of this study was to understand how health problems influenced work productivity. The combination of quantitative and qualitative data will offer the opportunity to better understand the causal mechanisms involved in early retirement and productivity at work [65]. 


\subsection{Data Management and Analyses}

All data are stored in secured computer systems. Data from different waves are merged into SPSS system files to enable longitudinal data analyses. Data are mainly analysed using SPSS software, with several analytical techniques. Linear regression analyses are carried out to examine the relation between determinants and continuous outcome measures, such as productivity. Logistic regression analyses are carried out to examine the contribution of determinants to dichotomous outcome measures, including transitions to early retirement, job-job mobility, etc. General Linear Models (GLM) are used to examine changes over time in continuous variables, including health, work motivation, workability, productivity, etc. GEE and multilevel techniques are used to combine several waves of data in repeated regression analyses. Finally, structural equation modelling with LISREL is used to examine the STREAM research framework (Figure 1) as a whole, i.e. the contribution of the full range of determinants to an outcome variable through the central explanatory variables in a single model.

It should be noted that the variables in the research framework to some extend overlap with each other. Therefore, when answering specific research questions, we will examine the associations between these variables and check for multicollinearity.

\section{RESULTS AND DISCUSSION}

\subsection{Transitions in Employment between T1 and T3}

At present, three waves of data collection are available, with 10,952 observations with full data. In this paragraph we present descriptive results of the major transitions in employment between the three measurements. These results give an impression of the number of transitions that are to be expected during the course of the study, and are compared with the expectations that were formulated in the power analysis for this study.

As presented in Table 3, of the 8,752 employees at the baseline measurement (T1) with full data, $84 \%$ remained an employee at all three measurements, $13 \%$ left the workforce, and $1 \%$ became self-employed. Moreover, $111(1.3 \%)$ of the employees had lost their job at the second measurement, but had re-entered the workforce at the third measurement. Of the self-employed persons at T1, 81\% remained self-employed at all three measurement, $6 \%$ became an employee, and $9 \%$ left the workforce. It is noteworthy that a much higher percentage of those self-employed became employee, than the reverse transition from employment to self-employment. Finally, of the non-employed persons, $84 \%$ remained nonemployed, $11 \%$ became employee, and $2 \%$ became self-employed.

More detailed analyses revealed that of the 2,256 employees aged 60 to 63 years at baseline with data on T1 and T2, 257 retired early in the first year of follow-up (11.4\%), excluding those who indicated that they were also disabled for work or unemployed at T2 [66]. This is a much lower percentage than the $31 \%$ that we had anticipated in our power analysis. Further analyses among the employees who remained employed, showed that $475(6.2 \%)$ changed jobs (external mobility) between T1 and T3, and 1,054 (14.8\%) changed position at their current employer (internal mobility). 
Table 3. Transitions in work status between $\mathrm{T} 1, \mathrm{~T} 2$ and $\mathrm{T} 3$ for participant with full data

\begin{tabular}{|c|c|c|c|c|c|}
\hline T1 & T2 & T3 & number & $\%$ status T1 & $\%$ total \\
\hline \multirow{9}{*}{ Employee } & \multirow{3}{*}{ Employee } & Employee & 7,379 & $84.3 \%$ & $67.4 \%$ \\
\hline & & Self-employed & 50 & $0.6 \%$ & $0.5 \%$ \\
\hline & & Non-employed & 632 & $7.2 \%$ & $5.8 \%$ \\
\hline & \multirow{3}{*}{ Self-employed } & Employee & 13 & $0.1 \%$ & $0.1 \%$ \\
\hline & & Self-employed & 41 & $0.5 \%$ & $0.4 \%$ \\
\hline & & Non-employed & 14 & $0.2 \%$ & $0.1 \%$ \\
\hline & \multirow{3}{*}{ Non-employed } & Employee & 95 & $1.1 \%$ & $0.9 \%$ \\
\hline & & Self-employed & 16 & $0.2 \%$ & $0.1 \%$ \\
\hline & & Non-employed & 512 & $5.9 \%$ & $4.7 \%$ \\
\hline \multirow{9}{*}{ Self-employed } & \multirow{3}{*}{ Employee } & Employee & 29 & $4.1 \%$ & $0.3 \%$ \\
\hline & & Self-employed & 14 & $2.0 \%$ & $0.1 \%$ \\
\hline & & Non-employed & 3 & $0.4 \%$ & $0.0 \%$ \\
\hline & \multirow{3}{*}{ Self-employed } & Employee & 16 & $2.3 \%$ & $0.1 \%$ \\
\hline & & Self-employed & 573 & $80.9 \%$ & $5.2 \%$ \\
\hline & & Non-employed & 35 & $4.9 \%$ & $0.3 \%$ \\
\hline & \multirow{3}{*}{ Non-employed } & Employee & 4 & $0.6 \%$ & $0.0 \%$ \\
\hline & & Self-employed & 6 & $0.8 \%$ & $0.1 \%$ \\
\hline & & Non-employed & 28 & $4.0 \%$ & $0.3 \%$ \\
\hline \multirow{9}{*}{ Non-employed } & \multirow{3}{*}{ Employee } & Employee & 102 & $6.8 \%$ & $0.9 \%$ \\
\hline & & Self-employed & 2 & $0.1 \%$ & $0.0 \%$ \\
\hline & & Non-employed & 39 & $2.6 \%$ & $0.4 \%$ \\
\hline & \multirow{3}{*}{ Self-employed } & Employee & 2 & $0.1 \%$ & $0.0 \%$ \\
\hline & & Self-employed & 12 & $0.8 \%$ & $0.1 \%$ \\
\hline & & Non-employed & 11 & $0.7 \%$ & $0.1 \%$ \\
\hline & \multirow{3}{*}{ Non-employed } & Employee & 62 & $4.2 \%$ & $0.6 \%$ \\
\hline & & Self-employed & 15 & $1.0 \%$ & $0.1 \%$ \\
\hline & & Non-employed & 1,247 & $83.6 \%$ & $11.4 \%$ \\
\hline Total & & Total & 10,952 & & $100.0 \%$ \\
\hline
\end{tabular}

\section{CONCLUSION}

The Study on Transitions in Employment, Ability and Motivation (STREAM) is a large-scale longitudinal study among employees, self-employed and non-employed persons aged 45 to 64 years in the Netherlands. STREAM aims to contribute to healthy and productive labour participation among persons aged 45 years and older, and to fill a number of important gaps in knowledge concerning sustainable employability of older workers. Moreover, through linkage to national register data, we will be able to follow future transitions in employment in the years after data collections have ended. This study is an important step to further our understanding on the factors that influence the labour participation of the older workforce.

In our power calculation we assumed that relatively many persons would make a transition from work to early retirement during the study period. However, the actual number of transitions to early retirement between the first two measurements was much lower than anticipated. Since the power calculation was based on one year of follow-up and the design of our study covers two more years, we are confident that we will observe sufficient transitions from work to early retirement to answer our research questions. Moreover, finding a lower number of transitions to early retirement than anticipated is also an interesting result, which may be due to the changing regulations with regard to retirement age and pension benefits during follow-up. Early retirement is becoming financially less 
feasible for many older individuals. This means that STREAM is timed at an interesting age, and we hope to observe how these changes in regulations affect the labour participation and sustainable employability among older workers.

The present study will provide information on the relative importance of the determinants of transitions in employment and work productivity, and how changes in these factors (e.g., health changes, job mitigation) affect these outcomes. Moreover, insight in the role of the ability, motivation and opportunity to work among older persons will be obtained. This knowledge is highly important for developing work-related interventions and policies that promote sustainable employability among older workers in the Netherlands. The results can be used to improve national legislation at the macro level, to improve policies and interventions of employers at the meso level, and to develop interventions empowering individuals at the micro level. These policies and interventions will need to be developed further together with different stakeholders, including representatives from the government, employers and employees, and need to be tested in pilot studies.

Cooperation with comparable cohort studies in other European countries, including Germany, Ireland, and Denmark, will be sought to examine how differences in contextual variables, such as the social security system and cultural differences, affect the role of the determinants of transitions in employment and work productivity. Preferably, in addition to comparing results across cohort studies in North-Western Europe, also cohort studies in Southern European and Non-European countries, with quite different social security systems and labour markets, would be included in such cross-national comparisons to examine the generalizability of the results.

\section{CONSENT}

Participants were explicitly asked in the online questionnaire at baseline whether they consented to link their answers to register data at Statistics Netherlands. Furthermore, participants who were invited to partake in the qualitative studies had consented to be contacted and had provided their telephone numbers.

\section{ETHICAL APPROVAL}

The study protocol for STREAM has been presented to the Medical Ethical Review Board of VU University Medical Centre. The Board positively advised on this study, but deemed an official approval according to the Medical Research Act unnecessary.

\section{ACKNOWLEDGEMENTS}

STREAM has been designed and conducted by TNO, in close cooperation with VU University Medical Centre, and Erasmus Medical Centre. STREAM is carried out with financial support from the Dutch Ministry for Social Affairs and Employment.

\section{COMPETING INTERESTS}

Authors have declared that no competing interests exist. 


\section{REFERENCES}

1. Eurostat. Europe in figure: Eurostat yearbook 2008. Luxembourg: Eurostat European Commission; 2008.

2. Euwals R, de Mooij R, Van Vuuren D. Rethinkingretirement. From participation towards allocation. Den Haag: CPB Netherlands Bureau for Economic Policy Analysis; 2009.

3. Statistics Netherlands. From work to retirement: Persons aged 55 and older 2012; Available:http://statline.cbs.nl/StatWeb/publication/?DM=SLNL\&PA=80396ned\&D1=1, 9\&D2=0\&D3=0\&D4=0\&D5=0-2\&D6=0-2,8,15\&D7=0\&D8=0,3,6-11\&VW=T. Accessed 2/4, 2013.

4. $\quad$ Statistics Netherlands. Statistics Netherlands, Labour force: Gender and age. 2012; Available:http://statline.cbs.nl/StatWeb/publication/?DM=SLNL\&PA=71738NED\&D1= 3,6-7,22-25\&D2=a\&D3=0,4-5\&D4=0\&D5=51\&HDR=G1,T\&STB=G2,G3,G4\&VW=T. Accessed 2/4, 2013.

5. van den Berg TI, Elders LA, Burdorf A. Influence of health and work on early retirement. J OccupEnvironMed 2010;52(6):576-583.

6. Henkens $\mathrm{K}$, van Dalen $\mathrm{H}$, van Solinge $\mathrm{H}$. De vervagende grens tussen werk en pensioen. Over doorwerken, doorstarten en herintreders [The dissolving border between work and pension. About working longer, restarting and re-entering]. Den Haag: NIDI; 2009.

7. Damman M, Henkens K, Kalmijn M. The impact of midlife educational, work, health, and family experiences on men's early retirement. Journals of Gerontology - Series B Psychological Sciences and Social Sciences. 2011;66 B(5):617-627.

8. Herrbach $\mathrm{O}$, Mignonac K, Vandenberghe C, Negrini A. Perceived HRM practices, organizational commitment, and voluntary early retirement among late-career managers. Hum Resour Manage. 2009;48(6):895-915.

9. Fischer JAV, Sousa-Poza A. The institutional determinants of early retirement in Europe. Londen: Department of Economics, University of St. Gallen; 2006.

10. Lund T, Iversen L, Poulsen KB. Work environment factors, health, lifestyle and marital status as predictors of job change and early retirement in physically heavy occupations. Am J Ind Med. 2001;40(2):161-169.

11. Wanberg CR. The individual experience of unemployment. Annu Rev Psychol. 2012;63:369-396.

12. Vlasveld MC, van der Feltz-Cornelis CM, Bultmann U, Beekman AT, van Mechelen W, Hoedeman R, et al. Predicting return to work in workers with all-cause sickness absence greater than 4 weeks: a prospective cohort study. J Occup Rehabil. 2012;22(1):118-126.

13. Heyma AS, van der Werff S, Prins J. Baten van baan-baanmobiliteit [Benefits of job mobility] . Amsterdam: SEO; 2009.

14. $\mathrm{Ng}$ TWH, Sorensen KL, Eby LT, Feldman DC. Determinants of job mobility: A theoretical integration and extension. J Occup Organ Psychol. 2007 Sep;80(3):363386.

15. Sanders J, van Wijk E, Dorenbosch L. Arbeis markt transities van laagopgeleiden [Labour market transitions among lower educated persons]. In: Van Gaalen R, Sanders J, Smits W, Ybema JF, editors. Dynamiek op de Nederlandse arbeidsmarkt: De focus op kwetsbare groepen Den Haag: CBS. 2011;43-60.

16. Zwinkels W, Ooms D, Sanders J. Omvang, aard en achtergronden van baan-baanmobiliteit [Magnitude, nature and background of job mobility]. Den Haag: RWI; 2009.

17. Ybema JF, Geuskens GA. Willen we langer doorwerken? [Do we want to continue working?]. Tijdschrift voor gezondheidswetenschappen. 2011;89:72-74. 
18. Alavinia SM, Molenaar D, Burdorf A. Productivity loss in the workforce: associations with health, work demands, and individual characteristics. Am $\mathrm{J}$ Ind Med. 2009;52(1):49-56.

19. van den Heuvel SG, Geuskens GA, Hooftman WE, Koppes LL, van den Bossche SN. Productivity loss at work; health-related and work-related factors. Journal of Occupational Rehabilitation. 2010;20(3):331-339.

20. Meerding WJ, IJzelenberg W, Koopmanschap MA, Severens JL, Burdorf A. Health problems lead to considerable productivity loss at work among workers with high physical load jobs. J ClinEpidemiol. 2005 May;58(5):517-523.

21. van den Berg TI, Robroek SJ, Plat JF, Koopmanschap MA, Burdorf A. The importance of job control for workers with decreased work ability to remain productive at work. Int Arch Occup Environ Health. 2011 Aug;84(6):705-712.

22. Nagami M, Tsutsumi A, Tsuchiya M, Morimoto K. Job control and coworker support improve employee job performance. Ind Health. 2010;48(6):845-851.

23. Wright TA, Cropanzano R. Psychological well-being and job satisfaction as predictors of job performance. J Occup Health Psychol. 2000;5(1):84-94.

24. Fouarge $D$, Schils $T$. The effect of early retirement incentives on the training participation of older workers. Labour. 2009;23(SUPPL. 1):85-109.

25. Lahelma E, Laaksonen M, Lallukka T, Martikainen P, Pietiläinen O, Saastamoinen $P$, et al. Working conditions as risk factors for disability retirement: A longitudinal register linkage study. BMC Public Health 2012;12(1).

26. World Health Organization. Health is a state of complete physical, mental and social well-being and not merely the absence of disease or infirmity. Proceedings and final acts of the Internal Health Conference, New York 19 June to 22 July 1946 Geneva: World Health Organization. 1948;100.

27. Bakker AB, Demerouti E. The Job Demands-Resource model: state of art. Journal of Managerial Psychology. 2006;22(3):309-328.

28. Piasentin KA, Chapman DS. Subjective person-organization fit: Bridging the gap between conceptualization and measurement. Journal of Vocational Behavior. 2006;69:202-221.

29. van Loo J, de Grip A, de Steur M. Skills Obsolescence: Causes and Cures. Maastricht: Research Centre for Education and the Labour Market (ROA); 2001.

30. Kivimäki M, Nyberg ST, Batty GD, Fransson El, Heikkilä K, Alfredsson L, et al. Job strain as a risk factor for coronary heart disease: A collaborative meta-analysis of individual participant data. Lancet. 2012;380(9852):1491-1497.

31. Appelbaum E, Bailey T, Berg P, Kalleberg AL. Manufacturing Advantage: Why HighPerformance Work Systems Pay Off. Ithaca NY: Cornell University Press. 2000.

32. Rothschild ML. Carrots, sticks and promises: A conceptual framework for the management of public health and social issue behaviors. Journal of Marketing. 1999;63:24-37.

33. IImarinen J. Work ability--a comprehensive concept for occupational health research and prevention. Scand J Work Environ Health. 2009;35(1):1-5.

34. Albert B. Social cognitive theory of self-regulation. Organ Behav Hum Decis Process. 1991;50(2):248-287.

35. Ryan RM, Deci EL. Self-determination theory and the facilitation of intrinsic motivation, social development, and well-being. American Psychologist. 2000;55:6878.

36. Kahn HA, Sempos CT. Statistical methods in epidemiology. New York: Oxford University Press; 1989. 
37. Statistics Netherlands, Netherlands Institute for Social Research. Povertydescription 2011. Den Haag: Centraal Bureau voor de Statistiek (CBS);Sociaal en Cultureel Planbureau (SCP); 2011.

38. Theeuwes J, Koopmans C. The end of Okun's law. Amsterdam: SEO; 2010.

39. Kraan K, Hooftman W, de Jong T. Cohort Study Social Innovation (CSI) 2008-2010; Methodology and description of the first measurement (2008). Hoofddorp: TNO Kwaliteit van Leven; 2009.

40. Ybema JF, Sanders J, De Vroome E. Study on Health at Work (SHAW). Methodology and first results 2004-2006. Hoofddorp: TNO Kwaliteit van Leven; 2010.

41. Ware JJ, Kosinski M, Keller SD. A 12-Item Short-Form Health Survey: construction of scales and preliminary tests of reliability and validity. Med Care. 1996;34(3):220-233.

42. Ware JEJ, Sherburne CD. The MOS 36-item short-form health survey (SF-36). I. Conceptual framework and item selection. Med Care. 1992;30(6):473-483.

43. Roberts RE, Vernon SW. The Center for Epidemiologic Studies Depression Scale: its use in a community sample. Am J Psychiatry. 1983;140(1):41-46.

44. Schaufeli WB, Bakker A. UBES. Utrechtse Bevlogenheidschaal [Utrecht Work Engagement Scale]. Utrecht: Sectie Psychologie van Arbeid, Gedrag en Organisatie. Universiteit Utrecht; 2003.

45. Karasek R. Job Content Questionnaire and user's guide. Lowell: University of Massachusetts, Department of work environment; 1985.

46. Kristensen TS, Hannerz H, Hogh A, Borg V. The Copenhagen Psychosocial Questionnaire-a tool for the assessment and improvement of the psychosocial work environment. Scand J Work Environ Health. 2005;31(6):438-449.

47. Furunes $T$, Mykletun RJ. Age discrimination in the workplace: validation of the Nordic Age Discrimination Scale (NADS). Scand J Psychol. 2010;51(1):23-30.

48. Pearlin LI, Lieberman MA, Menaghan EG, Mullan JT. The stress process. J Health Soc Behav. 1981;22(4):337-356.

49. Koppes L, de Vroome E, Mol M, Janssen B, van den Bossche S. Netherlands Working Conditions Survey 2008. Methodology and descriptive results. Hoofddorp: TNO Kwaliteit van Leven; 2009.

50. Hildebrandt VH, Bongers PM, van Dijk FJ, Kemper HC, Dul J. Dutch Musculoskeletal Questionnaire: description and basic qualities. Ergonomics. 2001;10;44(12):10381055.

51. Spoor E, de Jonge J, Hamers JPH. Nu even niet...! Of toch wel...! Een dagboekstudie naar detachment en creativiteit [Take a break...! Or better not...! A daily survey study on detachment and creativity]. Gedrag \& Organisatie. 2010;23(4):296-315.

52. Ybema JF, van den Bos K. Effects of organizational justice on depressive symptoms and sickness absence: a longitudinal perspective. Soc Sci Med. 2010;70(10):16091617.

53. Boer EM, Bakker AB, Syroit JE, Schaufeli WB. Unfairness at work as a predictor of absenteeism. Journal of Organizational Behavior. 2002;23:181-197.

54. van Veldhoven M, Dorenbosch L. Age, proactivity and career development. Career Development International. 2008;13(2):112-131.

55. Eurofound. Fourth European Working Conditions Survey 2005. Dublin: Eurofound; 2009.

56. Tuomi K, Ilmarinen J, Jahkola A, Katajarinne L, Tulkki A. Work Ability Index. 2nd revised ed. Helsinki: Finnish Insitute of Occupational Health; 1998.

57. Oeij P, de Vroome E, Sanders J, van den Bossche S. Employer Work Survey 2008. Methodology and descriptiveresults. Hoofddorp: TNO; 2009. 
58. Van Roijen L, Essink-Bot M, Koopmanschap MA, Bonsel G, Rutten FFH. Labor and health status in economic evaluation of health care: The health and labor questionnaire. Int J Technol Assess Health Care. 1996;12(3):405-415.

59. Brouwer WB, Koopmans chap MA, Rutten FF. Productivity losses without absence: measurement validation and empirical evidence. Health Policy. 1999;48(1):13-27.

60. Koopmans L, Bernaards CM, Hildebrandt VH, Schaufeli WB, De Vet HCW, Van Der Beek AJ. Conceptual frameworks of individual work performance: A systematic review. Journal of Occupational and Environmental Medicine. 2011;53(8):856-866.

61. Schreurs PJG, Van De Willige G, Brosschot JF, Tellegen B, Graus GMH. De Utrechtse Coping Lijst: UCL [Utrecht Coping List]. Lisse: Swets\&Zeitlinger; 1993.

62. De Wind A, Geuskens GA, Reeuwijk KG, Westerman MJ, Ybema JF, Burdorf A, et al. Pathways through which health influences early retirement: A qualitative study. BMC Public Health. 2013;13(1).

63. Reeuwijk KG, De Wind A, Westerman MJ, Ybema JF, Van Der Beek AJ, Geuskens GA. 'All those things together made me retire': Qualitative study on early retirement among Dutch employees. BMC Public Health. 2013;13(1).

64. Leijten F, van den Heuvel S, Geuskens G, Ybema JF, de Wind A, Burdorf A, et al. How do Older Employees with Health Problems Remain Productive at Work? A Qualitative Study. J OccupRehabil.2013;23(1):115-124.

65. Malterud K. Qualitative research: standards, challenges, and guidelines. Lancet. 2001;11;358(9280):483-488.

66. de Wind A, Geuskens GA, Ybema JF, Blatter BM, Burdorf A, Bongers PM, et al. Health, job characteristics, skills, and social and financial factors in relation to early retirement - results from a longitudinal study in the Netherlands. Scand J Work Environ Health. 2013 Oct 16.

(C) 2014 Ybema et al.; This is an Open Access article distributed under the terms of the Creative Commons Attribution License (http://creativecommons.org/licenses/by/3.0), which permits unrestricted use, distribution, and reproduction in any medium, provided the original work is properly cited.

Peer-review history:

The peer review history for this paper can be accessed here: http://www.sciencedomain.org/review-history.php?iid=358\&id=12\&aid=2671 